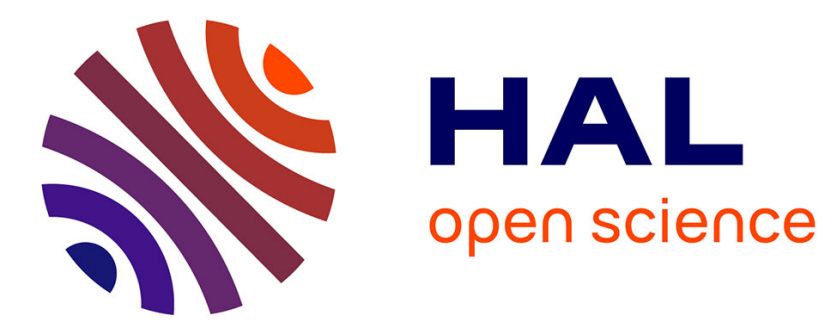

\title{
Space for Seriousness?
}

Heinrich Söbke

\section{To cite this version:}

Heinrich Söbke. Space for Seriousness?. 14th International Conference on Entertainment Computing (ICEC), Sep 2015, Trondheim, Norway. pp.482-489, 10.1007/978-3-319-24589-8_44 . hal-01758438

\section{HAL Id: hal-01758438 \\ https://hal.inria.fr/hal-01758438}

Submitted on 4 Apr 2018

HAL is a multi-disciplinary open access archive for the deposit and dissemination of scientific research documents, whether they are published or not. The documents may come from teaching and research institutions in France or abroad, or from public or private research centers
L'archive ouverte pluridisciplinaire HAL, est destinée au dépôt et à la diffusion de documents scientifiques de niveau recherche, publiés ou non, émanant des établissements d'enseignement et de recherche français ou étrangers, des laboratoires publics ou privés. 


\title{
Space for seriousness? \\ Player Behavior and Motivation in Quiz Apps
}

\author{
Heinrich Söbke \\ Bauhaus-Universität Weimar, Bauhaus-Institute for Infrastructure Solutions (b.is), Germany \\ heinrich.soebke@uni-weimar.de
}

\begin{abstract}
Quiz apps as a genre have seen a huge leap in distribution over the past year. Their applicability to any subject matter of any subject area, along with their ubiquitous availability, means they could be considered as a potential learning tool. However, popular quiz apps are optimized for entertainment. Furthermore, multiple choice questions have so far been used predominantly for assessment but not for learning. We have examined popular quiz apps in a two-stage approach. First, test persons played quiz apps of their choice on a daily basis and took field notes. A questionnaire for an online survey was then developed from the results. Our research questions were: (1) What are the contexts in which quiz apps are played? (2) What game mechanics are perceived as motivating? The survey with 396 participants helped us identify usage characteristics and the main motivations for utilizing these apps. Among relevant findings are a distinct willingness to learn and the phenomenon of sociability, i.e. the motivation to play with and compete against friends.
\end{abstract}

Keywords: quiz apps $\cdot$ mobile gaming $\cdot$ mobile learning $\cdot$ game design $\cdot$ educational app

\section{Introduction}

The QuizClash app [1] came to the public's notice in Germany in the last months of 2013. This app is based on quizzes and employs simple game mechanics. Two players compete by answering multiple choice questions asynchronously in six rounds. The player with the most correct answers wins the match and is rewarded with a number of points. These points are accumulated and determine the rank within the overall community of players. The app has reached a huge audience: in January 2014 it had 8 million players in Germany [2], and by the end of 2014 almost 20 million players had created an account in the German version. Furthermore, a TV show in German publicservice broadcasting has been built around this game [3,4].

QuizClash is just one example of a popular quiz app. There are other apps which enjoy similar popularity, as $Q u i z U p[5,6]$. So there seems to be a tremendous potential for quiz apps. From an educational point of view it is very significant that there is evidence for learning. Pawelka et al. [7] received first positive results employing a QuizClash-like prototype, although the sample size was small. During our own game play we too noticed learning effects. Furthermore, reports from players themselves often indicate that learning is both a result of and a requirement for playing such a game successfully $[4,8]$. The question thus arises whether quiz apps can be used as an educational tool. They seem to employ an attractive and proven game principle. Furthermore, they manifest all the characteristics of mobile apps that lead to a huge number of players and are recognized as beneficial for learning, namely easy accessibility, ubiquitous availability and connectivity, to name but a few [9]. Additionally, they can be applied to a great range of subject areas and knowledge levels $([10,11])$.

In order to evaluate in how far these theoretical assumptions apply to the usage of quiz apps in the field, we conducted an online survey with two main research questions (RQs) in mind: What usage contexts are prevalent? $(R Q 1)$ and What are the main elements that motivate individuals to play these games?(RQ 2). Amongst other, RQ 1 aims at the hypothesis that apps are used in a 
more casual manner and support short sessions of play. RQ 2 should help to identify those game elements which lead to a high attraction of quiz apps.

Our article is structured as followed: First we describe the experiment design, the online survey and different aspects of its results: the context for playing quiz apps is delineated (RQ 1). Thereafter we discuss players' preferences (RQ 2). Finally, we present the most important findings, develop answers to the research questions and summarize them in a conclusion.

\section{Survey}

\subsection{Method and demography}

We began our approach in an exploratory way. Eleven participants in a student project for educational media were each required to play a quiz app of their choice for at least five minutes a day. They were asked to write down their experiences as field notes. After one week, field notes were merged in order to exchange experiences. Field notes continued to be taken for another week. These experiences served as input for the online survey. For example, it was observed that QuizClash [1] had been used as a medium in a drinking game. From this we concluded that quiz apps may be played in company. We therefore asked about this characteristic in the survey.

The resulting online-survey consisted of 45 questions. A call for participation was distributed within the social environment of the student project. Both digital and non-digital channels were used. Pursuing the approach of snowball-sampling, we asked participants to forward the survey to their friends. Facebook as a social network service is one of the digital channels used. Friends and relatives were also addressed directly. The survey was open for participation for almost a month, from 15 December 2014 to 8 January 2015. There were 396 participants in all, aged from 14 to 65 years; the average age was 25.3 , the median $23.60 \%$ were female and $40 \%$ male. $33 \%$ indicated that they were working. Another $61 \%$ were students, either at university or an upper school.

$238(60 \%)$ of the participants confirmed their use of quiz apps. Reasons for not playing quiz apps are a lack of interest or time (79\%), not being aware of quiz apps $(20 \%)$, and not having an appropriate IT device (6\%). Other reasons given as textual responses include self-protection, quality of questions, data privacy concerns, no game partner and too many in-gameadvertisements. A conclusion from this distribution is that the lack of suitable hardware is not a significant reason not to play quiz apps. Those participants who denied playing quiz apps, have been asked if they play other quiz-based games. 108 stated not to such games at all, but 50 acknowledged. They were asked in an open question to describe, why they are attracted by these games (see Fig. 4).

\subsection{Contexts of playing quiz apps}

Device. Quiz apps are played predominantly on a smartphone. $89 \%$ of all participants named it as their device for using the app. Another $9 \%$ use it in combination with a tablet. Just $2 \%$ play a quiz app only on a tablet.

Usage profile. Only $5 \%$ of all participants refer to themselves as regular app users. We used a 5point Likert scale (1: sporadically - 5: regular) to get respondents to describe their regularity of use. More than $2 / 3$ of users chose an irregular usage pattern ( 1 and 2 points). 17\% could not decide. Results for the question "How often do you use your quiz app?" revealed a similar result (see Fig. 1). Again, $2 / 3$ claimed to use the app a few times a month. A small group of $4 \%$ said they used such an app for more than 30 minutes a day. Thus, while quiz apps are generally used more sporadically, there seems to be a small faction of players who play these apps intensively. We also asked how long players had been using quiz apps. 39\% have been playing for over a year, 59\% for less than a year but longer than a month. Some players stated that they had stopped playing quiz 
apps because the novelty appeal was no longer given and they were unable to detect any new elements. Nevertheless, there seems to be a tendency towards the long-term use of such apps.

\section{Frequency of usage}

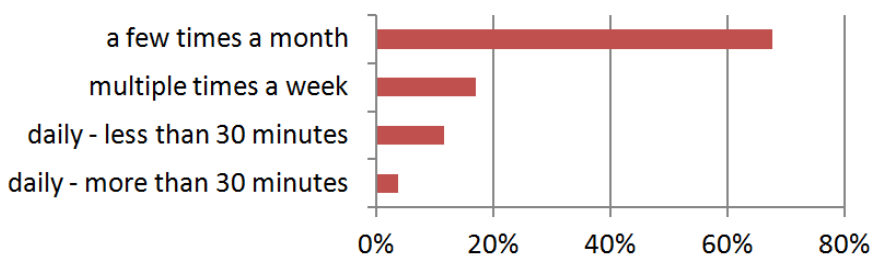

Fig. 1. How often do you use quiz apps? $(n=238)$

We wanted to know the situations in which quiz apps are used. There proved to be four main categories: apps are used mostly while travelling and commuting (68\%), followed by use in one's spare time (63\%), during breaks (48\%), and during work or lectures (44\%) (see Fig. 2). The last value may have been influenced by the high percentage of students in the survey. This value may also have been responsible for increasing the percentage of players who do not use sound because it is inappropriate for their environment. Among the answers in the "Other" category were hospital stay, before bedtime and on the toilet. This last answer is supported by Kientz et al. [12], who state that games are among gadget-based activities during a visit to the toilet.

\section{Situations to play}

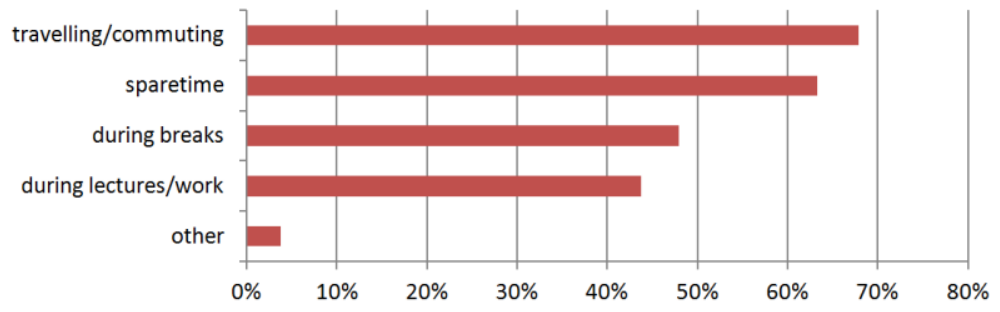

Fig. 2. In what situations do you use quiz apps? (n=238, multiple selections allowed)

\subsection{Players' preferences}

Motivation. We asked players to choose their preferred reasons for playing quiz apps from a given set of possible motivations (see Fig. 3). Almost $70 \%$ of players indicated that they used these apps as a pastime. The next most important reasons are sociability and the prospect of acquiring new general knowledge (each scoring more than 50\%). These reasons are followed by gametypical motivations such as competition, fun, entertainment and challenge. Importance is rarely attached to typical digital game features such as achievements and avatar development. Players are able to differentiate themselves from their friends and feel almost no peer pressure.

Reasons for playing quiz-based board games. A third (50) of all respondents (158) who do not play quiz apps indicated that they played other quizzes, mostly board games such as Trivial Pursuit [13] and Who Wants to Be a Millionaire? (75\%). They were asked to give reasons for playing those games in a non-digital form. It is striking to note that some reasons recur persistently - although no range of reasons was offered. These participants were not provided a closed question about their motivations as the app players, but an open question. Therefore we coded their answer using a coding scheme roughly based on the motivations indicated by the app placer faction. Fig. 4 shows the distribution of reasons named. Learning and sociability were mentioned by almost half the participants. These reasons were given more frequently than typical game attributes such as 
challenge and fun and entertainment. Motivations related to digital games, such as avatar development and achievements are not mentioned. Players differentiate between learning new facts and assessing their existing general knowledge.

\section{Reasons to play quiz apps}

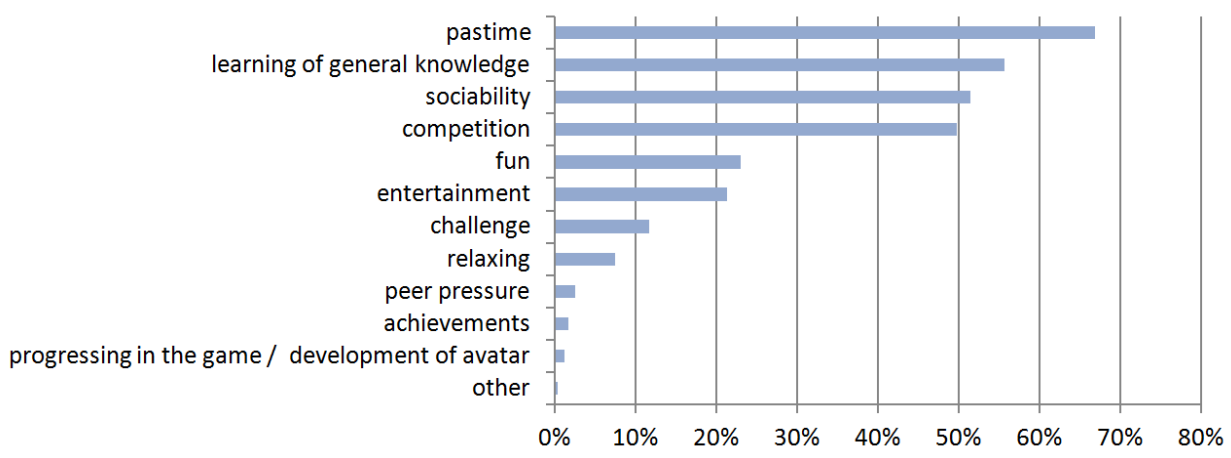

Fig. 3. Reasons for playing quiz apps ( $n=238$, multiple selections allowed)

\section{Reasons to play quiz-based games}

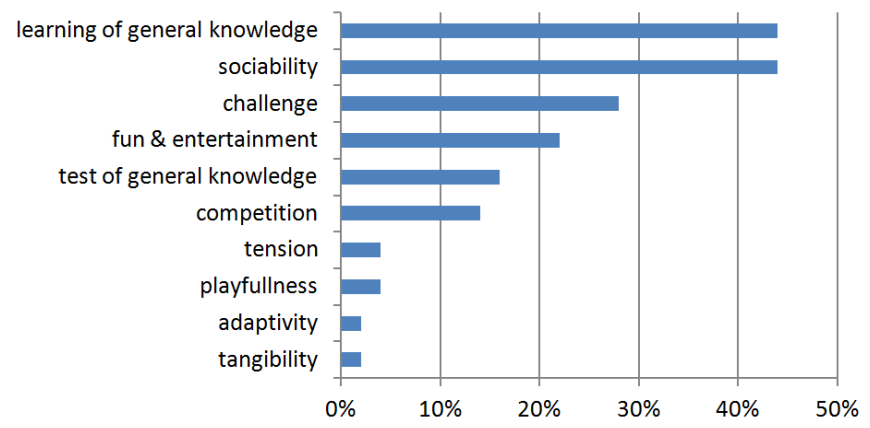

Fig. 4. Coded reasons ordered by frequency $(n=50)$

Opponents. Players prefer human opponents. We asked which type of opponent players usually faced: $92 \%$ compete with friends, $45 \%$ with random human opponents and $8 \%$ with bots. Another question looked at preferences for randomly assigned opponents or friends. $76 \%$ choose friends as their preferred opponents, while only $10 \%$ choose unknown opponents. For the remaining $15 \%$, their preference depends on the situation.

Communities and Groups. Communities and groups are considered valuable for learning [14]. Thus we are interested in the extent to which quiz apps foster communities and groups. First, sociability is one of the most important reasons for playing quiz apps. Furthermore the technical support of groups is suggested as an improvement for the app.

We wanted to know if players use quiz apps in collaboration with other players. More than half of the players do this at least sometimes. The company of friends enables reflection: in another question we asked if questions and their answers were discussed. 55\% mentioned direct conversations, and only $18 \%$ app chat and forums. Another $44 \%$ do not communicate about questions. Operating the app chat seems to be too cumbersome and using the forum means a change of medium. Therefore we assume that playing together with physically present friends is a prerequisite for reflection.

Games can foster friendship between players. Brüß et al. [15] found evidence in the social network game (SNG) Fliplife [16]: they asked players if they had developed friendships with other players 
originally unknown to them. $43 \%$ affirmed this assumption $(n=267)$. As a measurement of the strength of the friendships that evolved, they asked if players had met in reality. $32 \%$ answered with yes, 52\% had not met but did not exclude an encounter in future. We asked the same question: Has a player met a fellow player who s/he got to know in the quiz app? $8 \%$ of respondents confirmed. Although $8 \%$ is less than the equivalent percentage in the context of Fliplife, we consider it a remarkable figure. Fliplife is communication prone [17] whereas quiz apps rely more on previously formed groups.

Question topics. Quiz apps often allow the player to select the topic for the questions. So what are the preferences when it comes to choosing a topic? Half the players prefer to choose from a given set of topics. This is implemented in QuizClash [1]. Another third wish to select from a larger catalogue of topics as in QuizUp [5]. The others voted for the option "Random topic". In another question we asked about the principles followed when players are able to influence the topic. The most influential principles are own strengths (84\%) and personal interests (56\%). However, assumed weaknesses of the opponent are also decisive elements (46\%). Of negligible significance are "first topic that comes along" and "no strategy" (5\%). Two respondents said they chose a topic according to their personal weaknesses in order to increase learning success.

\section{Discussion}

In the responses to RQ 1 (What usage contexts are prevalent?) we found evidence that quiz apps are mostly used in a casual way: they are played whenever people have some spare time and can become habitual. However, for educational use, it is important to examine if the urge to learn can lead to more regular play. Players are motivated to use such apps by the prospect of socializing with their friends. This has been observed in two ways. Firstly, most players prefer to play against their friends. Secondly, apps are used as a medium for playing a game in company with or against other people. These findings are also relevant for RQ 2 (What are the main motivation elements to play these games?). Quiz apps are mostly regarded as a leisure pastime. However, from an educational point of view participants indicated a strong motivation to improve their knowledge. One has to ask if this motivation can facilitate the educational process: how do players react to blatantly educational content in such an app? How can such content be integrated without endangering the high level of engagement? How do motivations change if there is an educational content? These are questions which have to be clarified in order to enable an educational application of quiz apps.

The survey participants mainly played QuizClash [1]. It may therefore not be feasible to draw general conclusions from the results. Equally, the participant sample is relatively young and may not be representative. However, we spread the call for participation broadly and managed to recruit a significant number of non app-players, which is why we are confident of representing a significant part of population. Nevertheless, we cannot estimate the percentage of app players and therefore the market potential of this app genre purely on the basis of this online survey.

A remarkable finding from an analysis of the field notes was the reluctance to pay for these apps. After all, the authors of the field notes were required to play such an app intensively, and more than half the field notes contained complaints about "disturbing advertisements". In the case of QuizClash it would have taken less than $3 €$ to switch off advertisements. Some of the students reported that they never install apps they have to pay for. Others mentioned that they had never set up a payment channel for app purchases before. One is therefore faced with the challenge of funding such an app in a manner that keeps it readily accessible.

\section{Conclusions}

The hype about quiz apps has declined. This was indicated by some survey participants who have since moved on to the next viral app. However, our findings suggest that there is a considerable 
core of players who are engaged in quiz apps continuously over a long period of time. As one main motivation of the players is learning (and players have reported that they do in fact learn from the apps), we consider quiz apps to be a promising educational tool. This estimation is additionally based on the high demand for sociability expressed by quiz app players in the survey. Despites of the genre's casual character, fellow players are seen as persons and not as mere resources, as can be observed in SNGs [18], and is even attributed to players in traditional multiplayer online games [19]. Therefore, the fact that quiz app players enjoy common play with friends is a valuable asset. One area of weakness to emerge from our survey is that individual players seem to have affinities to specific domains of content. These affinities have to be taken into account in designing a concept for educational use. A further issue is the disinclination to pay for an app, a challenge which has to be resolved.

\section{$5 \quad$ References}

1. FEO Media AB: QuizClash | Challenge your friends!, http://www.quizclash-game.com/.

2. Trotier, K.: Fragen über Fragen - Die Wissens-App "Quizduell"erobert die Downloadcharts., http://www.zeit.de/2014/06/glosse-spiele-apps-quizduell.

3. ARD: Quizduell - ARD | Das Erste, http://www.daserste.de/unterhaltung/quizshow/quizduell/index.html.

4. Sagatz, K.: ARD setzt "Quizduell" zunächst nicht fort, http://www.tagesspiegel.de/medien/game-overard-setzt-quizduell-zunaechst-nicht-fort/9975924.html.

5. Plain Vanilla: QuizUp, https://www.quizup.com/.

6. Russolillo, S.: QuizUp: The Next "It" Game App?, http://live.wsj.com/video/quizup-the-next-it-gameapp/.

7. Pawelka, F., Wollmann, T., Stöber, J., Lam, T.V.: Erfolgreiches Lernen durch gamifiziertes E-Learning. In: Plödereder, E., Grunske, L., Schneider, E., and Ull, D. (eds.) 44. Jahrestagung der Gesellschaft für Informatik, Informatik 2014, Big Data - Komplexität meistern, 22.-26. September 2014 in Stuttgart, Deutschland. pp. 2353-2364. GI (2014).

8. Hardinghaus, B.: Interview mit LeBernd: Bernd Schneider über Quizduell, http://www.spiegel.de/netzwelt/games/interview-mit-lebernd-bernd-schneider-ueber-quizduell-a-951529.html.

9. Klopfer, E.: Augmented Learning: Research and Design of Mobile Educational Games. The MIT Press (2008).

10. Iz, H.B., Fok, H.S.: Use of Bloom's taxonomic complexity in online multiple choice tests in Geomatics education. Surv. Rev. 39, 226-237 (2007).

11. Collins, J.: Education techniques for lifelong learning: writing multiple-choice questions for continuing medical education activities and self-assessment modules. Radiogr. a Rev. Publ. Radiol. .... 543-552 (2005).

12. Kientz, J.A., Choe, E.K., Truong, K.N.: Texting from the Toilet: Mobile Computing Use and Acceptance in Public and Private Restrooms. CHI'13 (2013).

13. Bellis, M.: The History of Trivial Pursuit, http://inventors.about.com/library/inventors/bl_trivia_pursuit.htm.

14. Lave, J., Wenger, E.: Situated learning: legitimate peripheral participation. Cambridge University Press (1991).

15. Brüß, F., Brunner, K., Hünemörder, J., Kühn, S., Meisgeier, K.: Fliplife als virtueller Third Place, (2014).

16. Fliplife: Fliplife, http://fliplife.com/.

17. Söbke, H., Londong, J.: A Social Network Game as virtual Third Place: Community Enabler in Virtual Learning Environments? Proceedings of World Conference on Educational Multimedia, Hypermedia and Telecommunications 2015. pp. 518-531. Association for the Advancement of Computing in Education (AACE). (2015).

18. Söbke, H.: Gaming a Non-Game? A Long Term (Self-)Experiment about FarmVille. Well Play. 4, 215 262 (2015).

19. Yee, N.: The Proteus Paradox: How Online Games and Virtual Worlds Change Us-And How They Don't. Yale University Press (2014). 